Socialist Studies / Études socialistes 8 (1) Winter 2012

Copyright $\odot 2012$ The Author(s)

Article

\title{
FACTS, PRINCIPLES AND THE THIRD MAN ${ }^{1}$
}

\author{
LEA YPI \\ Government Department, London School of Economics and Political Science. \\ London, United Kingdom. ${ }^{2}$
}

\begin{abstract}
In the dialogue entitled "Parmenides" Plato introduces an objection to his own theory of ideas, one that he never managed to answer, dubbed by Aristotle as the "Third Man" argument. According to that objection, the theory of ideas is threatened with infinite regress when examining why a specific Platonic form (say, justice) is predicated of a particular set of facts. This article seeks to show how any defence of fact-insensitive principles like the one
\end{abstract}

\footnotetext{
${ }^{1}$ An earlier version of this paper was presented at the panel on "Political Normativity", ECPR Joint Sessions in Lisbon. I am grateful to members of that audience as well as to Dimitris Efthimiou, Katrin Flikschuh, Bob Goodin, Tamara Jugov, Rob Jubb, Patrick Tomlin, Laura Valentini, Jonathan White as well as to the editor and three anonymous reviewers of this journal for their extremely helpful written comments.

${ }^{2}$ Lea Ypi is Lecturer in Political Theory in the Government Department, London School of Economics, and Adjunct Professor in Philosophy at the Research School of Social Sciences, Australian National University. Before joining the LSE, she was a Post-doctoral Prize Research Fellow at Nuffield College (Oxford) and a researcher at the European University Institute where she obtained her PhD. Her research interests are in normative political theory (including democratic theory, theories of justice, and issues of migration and territorial rights), Enlightenment political thought (especially Kant), and nationalism in the intellectual history of the Balkans. Her articles have appeared (among others) in The Journal of Political Philosophy, Philosophy and Public Affairs, and The American Political Science Review. Her book Global Justice and Avant-Garde Political Agency has recently been published by Oxford University Press. She may be reached at 1.l.ypi@lse.ac.uk.
}

Lea Ypi est 'lecturer' en théorie politique dans le département de gouvernement, London School of Economics (LSE), et professeur associé de philosophie à l'Ecole de Recherche en Sciences Sociales, Australian National University. Avant de joindre LSE, elle a obtenu un prix pour ses recherches postdoctorales à Nuffield College (Oxford), après avoir été chercheur à l'European University Institute, où elle a obtenu son doctorat. Ses recherches sont dans le domaine de la théorie politique normative (entre autres, la théorie démocratique, les théories de justice et des débats sur le migration et les droits territoriaux), la pensée politique des Lumières (surtout Kant) et le nationalisme dans l'histoire intellectuelle des Balkans. Ses articles ont été publiés dans des revues telles que The Journal of Political Philosophy, Philosophy and Public Affairs, et The American Political Science Review. Son livre, Global Justice and AvantGarde Political Agency a été publié récemment par Oxford University Press. Elle peut être jointe à 1.1.ypi@lse.ac.uk. 
offered by G.A. Cohen in his recent book "Rescuing Justice and Equality" is vulnerable to a similar objection. Cohen wants to insist that, when showing why facts support principles, the process of reason-giving is finite and terminates in fact-independent comprehensive principles. But something like the Third Man argument undermines Cohen's conclusion just as it does Plato's. The search for ultimate fact-independent principles is indeed threatened by infinite regress.

\section{Résumé}

Dans le dialogue intitulé 'Parmenides' Platon introduit une objection à sa propre théorie des idées, à laquelle il n'a jamais réussi à répondre, appelée par Aristote l'argument du "troisième homme". D'après cette objection, la théorie des idées est menacée par une régression à l'infini lorsque l'on examine comment une forme platonique spécifique (par exemple, la justice) s'établit à partir d'un ensemble particulier de faits. Cet article cherche à montrer que toute défense de principes insensibles aux faits, comme celle offerte par G.A. Cohen dans son livre récent, Rescuing Justice and Equality est vulnérable à une objection semblable. Cohen voudrait montrer que lorsque l'on montre pourquoi certains faits soutiennent des principes, le processus explicatif est fini et se termine dans des principes complets qui sont indépendants des faits. Mais, quelque chose de semblable à l'argument du troisième homme est susceptible de saper les conclusions de Cohen comme celles de Platon. La recherche pour des principes ultimes indépendants des faits est bien menacé par une régression à l'infini.

\section{Keywords}

facts; G.A. Cohen; ideals; Plato; principles

\section{Mots clés}

faits; G.A. Cohen, idéaux; Platon; principes

I.

"Any attempt to realize the socialist ideal", claims G. A. Cohen in Why not Socialism? "runs up against entrenched capitalist power and individual human selfishness. Politically serious people must take these obstacles seriously". However, continues Cohen, "they are not reasons to disparage the ideal itself" (Cohen 2009: 80).

Marx would have been puzzled to read this statement. For him a society much like the one Cohen describes is precisely not "an ideal to which reality will have to adjust itself". It is not "a state of affairs to be established". It is "the real movement which abolishes the present state of things" (Marx 2000: 187).

Against Cohen's attempts to distinguish sharply between considerations of desirability and issues of feasibility, between the principles of socialism and the facts of 
the real world, ${ }^{3}$ stands Marx's conception whereby particular normative principles are framed in response to the very real conflicts expressing the need for them. Cohen, like Plato, is not afraid of political utopia. Marx, like Aristotle, perceives morality as shaped by the concrete social and political institutions in which human rationality manifests itself. In the case of the former, normative principles need to be carefully separated by the facts that we invoke in support of them. Otherwise, Cohen claims, such facts will contaminate our principles, and lead to confusion, confusion which, according to Cohen, "generates disoriented practice" (Cohen 2009: 80). In the case of Marx, any attempt to isolate principles from the world of facts, any theoretical stance which is also not a political one cultivates a doctrinaire spirit, the spirit of crass socialists who say: "Here is the truth, kneel down here!" (Marx 2000: 44.). For Marx, "to get its sins forgiven, humanity only needs to describe them as they are" (Marx 2000: 45).

Cohen's and Marx's statements reveal two different methodological positions, two alternative ways of thinking about the role of normative theory, its place in the world we experience, and its relation to existing political action. In the case of Cohen, theory takes pride of place; whether it reflects existing concerns and commitments, whether it motivates political action, and whether it succeeds in changing the world is all of secondary importance. Priority should be given to articulating fundamental principles, and only in a second step reflect on if and how they might relate to facts. In the case of Marx, on the other hand, political action fills theory with content; it is what makes it relevant, it is what gives it bite. Uncoupling normative theory from political cultivates moral hypocrisy and might end up even strengthening the endorsement of the existent state of affairs.

In the pages that follow I shall not engage with a direct comparison between these two different approaches. ${ }^{4}$ I shall instead limit myself to focusing on what I earlier called Cohen's Platonic utopianism, and examine the logical argument that underpins his attempt to conceptualize the proper relation between facts and principles. And I shall argue that Cohen, much like Plato, is vulnerable to an objection that Plato himself never managed to answer, dubbed by Aristotle as the "Third Man" argument. According to that objection, the theory of ideas is threatened with infinite regress when examining why a specific Platonic form (say, justice) is predicated of a particular set of facts. I will try to show how any defence of fact-insensitive principles like the one that has been offered in Cohen's methodological discussions on the relationship between facts and principles is vulnerable to a similar objection. Cohen insists that, when showing why facts support principles, the process of reason-giving is finite and terminates in fact-independent comprehensive principles. But something like the Third Man argument undermines that

\footnotetext{
${ }^{3}$ For further discussion of the issue, and an analysis of how the separation between desirability and feasibility requirements is also present in other writings of Cohen see Gilabert 2011.

${ }^{4}$ For a discussion of the virtues and limits of each see Ypi 2011, chapter 2.
} 
conclusion just as it does Plato's. The search for ultimate fact-independent principles is indeed threatened by infinite regress.

Of course, the fact that Cohen's enterprise is fraught with difficulties does not necessarily mean that Marx's method is the right way to go. But illustrating these difficulties might be instructive to point to the need for integrating with an alternative account, one which is more open to establishing constructive links between theory and practice, rather than insisting that normative theory matters no matter what the facts are.

The paper proceeds as follows. Section II illustrates the defence of fact-insensitive principles. Section III introduces the parallels between the search for fact-insensitive principles and Plato's defence of the role of ideas. Section IV explains how one famous objection to the theory of ideas - the "Third Man argument" - applies also to the defence of fact-insensitive principles. Section V takes this issue further in clarifying the premises of the Third Man argument and shows how they affect the defence of fact-insensitive principles. Section VI examines an important objection to the application of the Third Man argument to the defence of fact-insensitive principles. Section VII concludes.

\section{II.}

The defence of fact-insensitive principles (for short: "the thesis") can be summarized as follows: "A principle can reflect or respond to a fact only because it is also a response to a principle that is not a response to a fact". Or, to put it otherwise, "principles that reflect facts must, in order to reflect facts, reflect principles that don't reflect facts." (230). ${ }^{5}$

The defence of the fact-insensitivity of principles rests on three core premises. The first premise is the following:

G1: Whenever a fact supports a principle there is always an explanation for why $\mathrm{F}$ supports $\mathrm{P}$, i.e. an explanation of why F represents a reason to endorse $\mathrm{P}(236)$.

This premise does not receive or require too much attention. Cohen points out that the specific reason for which facts support principles is provided by the second premise of the argument. That second premise (which could also be stated conditionally) claims the following:

G2: The explanation invoked in the first premise implies a more ultimate principle that explains why F supports P.

\footnotetext{
${ }^{5}$ Citations in the text refer to page numbers of (Cohen 2008).
} 
The defence for this argument is, somewhat disappointingly, merely to challenge anyone reflecting on why that fact supports the principle to come up with an example in which the above does not occur. ${ }^{6}$ But on a less ad-hominem (and more logically pertinent reconstruction) it is easy to see how the premise relies on the combination of two assumptions. Both assumptions are implicit in the explanation that defenders of the thesis give for "why anything grounds what it grounds". The first assumption relies on the idea that given certain facts, there is always (at least) one more ultimate principle that explains why any set of facts gives us reasons to endorse a certain set of principles. Call this the "the one-over-many assumption". Cohen goes some way to clarifying further this assumption when arguing that once we admit, if only conditionally, that there is an explanation for why facts support principles, then a more ultimate principle is invoked (236).

The "one over-many-assumption" is itself strengthened by a supplementary argument. That argument claims that no set of facts supports a set of principles just by virtue of themselves - if it did there would be no need for further enquiry. Call this "the non-self explanation assumption". Cohen acutely notes that this assumption is only introduced in the second premise of the argument. Indeed, as far as the first premise is concerned, "it is allowed here to be an explanation (albeit a singularly unsatisfying one) of why $p$ (if it indeed does) supports $\mathrm{p}$ that they are the same proposition" (236). So the first premise of the argument allows for self-explanation but the second does not. The second premise therefore makes a stronger argument by adding to the first premise that it is implausible (or perhaps unsatisfying) to say that a claim supports itself simply by virtue of itself.

Notice that the one-over-many assumption and the non-self explanation assumption are distinct from each other. There may be cases in which the one-over-many assumption applies in such a way that allows for self-explanation. So for example, if we state that "people should not harm each other" and then ask why, we might respond: "because harm causes pain" and then conclude the reason-giving sequence with an utterance like "pain is bad". 7 If the utterance "pain is bad" were endorsed without further enquiry, it would play the role of a "one-over-many" assumption which does not deny the possibility of self-explanation; we could say that "pain is bad because pain is bad". In order to proceed with the sequence, as Cohen's argument requires, we ought to be able to deny the possibility for self-explanation to "pain is bad". Cohen never says that the "nonself explanation" premise only applies to facts and not to principles, and for good reasons;

\footnotetext{
${ }^{6}$ The weakness of the defence has already been noted in the excellent critique of Thomas Pogge, see (Pogge 2008: 456).

7 Notice that in Cohen's broad definition of fact, utterances of the type "pain is bad" are legitimately considered as factual descriptions (258).
} 
that would turn his entire argument into a petitio principii. But what then is to stop the sequence of interrogation from going on forever?

The answer to this question is provided by the third premise of the argument. ${ }^{8}$ That premise denies that the sequence of interrogation could proceed endlessly not by endorsing "self-explanation" but by relying on something often referred to as "the clarity of mind assumption", the idea that the person (or theory) affirming certain principles has a clear grasp both of the principles that she (it) holds and of the reasons for holding them $(233,237){ }^{9}$ The difficult question, to be raised at the end of the paper, is whether this premise (and the arguments that go with it) does the job that is required from it to prevent the logical flaw that, as we shall shortly illustrate, the argument independently generates. ${ }^{10}$ For now, let me put these caveats to one side and summarize the conclusion of the thesis.

The conclusion asserts that there is an ultimate fact-insensitive principle (or several such). ${ }^{11}$ The central contention of this paper, constructed with reference to a familiar objection that I will elaborate in the next few pages, is that the argument as it stands does not lead to such principle (or principles) but to a vicious logical problem. The objection I will introduce to support my claims shows that in a way similar to Plato's theory of ideas, the defence of fact-insensitive principles is indeed threatened with infinite regress.

\section{III.}

One does not need to engage in deep exegesis to illustrate some relevant similarities between the defence of the fact-insensitivity of principles and the Platonic

\footnotetext{
${ }^{8}$ Thomas Pogge notes the absence of an appropriately formulated third premise in Cohen's defence of factfree principles and proceeds to provide one in the following way: "Iteratively applied to any fact-sensitive principle, the elimination of facts terminates in a wholly fact-insensitive principle (which holds regardless of all facts)" (Pogge 2008: 456-7). Note however that only the "non-iterative application" part plays a significant role in this formulation. If we bracket that addition, Pogge's statement ceases to sound like a premise and already contains the conclusion of the argument.

${ }^{9}$ It is rather unfortunate that in responding to possible objections, Cohen has conceded that one could deny the clarity of mind requirement without damage to any of the argument's premises (247). If we are authorized to deny the clarity of mind then we are entitled to put to one side one of the main claims in support of the third premise. But it then ceases to be clear how the premise could be independently defended. I shall return to this issue in the following pages.

${ }^{10}$ In the final part of the paper I argue that the claims that are used to establish the third premise are not compatible with some of the restrictions Cohen places on the argument he presents. Readers interested only interested in this part of the paper but not to the analogy with Plato's theory of ideas, might also skip the pages that follow and go to the penultimate section.

${ }^{11}$ Cohen continues: "that will be exposed if you continue that interrogation for as long as may be necessary, and if the person knows what her principles are and why she holds them" (256).
} 
theory of ideas. In a particularly revealing passage of Rescuing Justice and Equality, Cohen records his agreement with the Platonic method of philosophical enquiry and its ability to transcend the facts of the world in the search for ultimate fact-insensitive moral principles. As he explicitly puts it:

I agree with the Socrato - Platonic view that led Socrates to reject illustrations of, for example, just behaviour as providing a proper answer to the question "What is Justice?": no list of examples reveals what it is about the examples that makes each an example of justice. Until we unearth the fact-free principle that governs our fact-loaded particular judgments about justice, we don't know why we think what we think just is just. And we have to retreat to (what we consider to be) justice in its purity to figure out how to institute as much justice as possible inside the cave (291).

To understand what is at stake in the identification with the Socratic-Platonic view, it may be worth unpacking this passing reference to Plato's allegory of the cave. A rough summary will suffice for our purposes. According to that famous Platonic allegory, the unfortunate inhabitants of the cave are born and have always lived under the ground, with their legs and necks tied in such a way that forces them to look straight and prevents them from turning their heads. The only thing that inhabitants of the cave are able to observe, and take to be real, are the walking and talking images reflected on the walls of the cave through a fire burning between them and the road. When one of the prisoners is set free to walk out of the cave, he is dazzled by the real light, pained to see the Sun and surprised to discover that the images and sounds that people in the cave have been exposed to, and have confused with reality, are but ephemeral shadows with no existence of their own.

In a way similar to the defence of fact-insensitive principles mentioned above, the point of the Platonic allegory is to illustrate how to think about ideas and in what way to perceive the relationship between first principles and the transitory, human experiences in which they are contingently reflected. Images in the cave have no independent standing; they simply cast the light that the fire and the Sun shed on them, just like factsensitive principles only obtain validity by appealing to the authority of more ultimate fact-insensitive principles. There is, of course, a relevant disanalogy. Plato seems ${ }^{12}$ committed to a kind of metaphysical foundationalism that defenders of the thesis we are examining carefully try to avoid. Yet not much that is relevant to the argument at this point depends on emphasizing that contrast. The similarity we are exploring relates to the

\footnotetext{
${ }^{12}$ I say "seems" because as I go on to illustrate below, one could also interpret Plato's thesis as being stated merely conditionally.
} 
process of reason-giving which underpins any attempt to clarify why facts may support principles. The relevant analogy therefore concerns the logic of the argument rather than its metaphysical or ontological or epistemological (or all of these in conjunction) premises. This is in keeping with the restrictions Cohen himself has placed on the argument, claiming that the defence of fact-insensitive principles, is neutral with regard to the "is-ought" controversy, the objectivity of principles, the prospects of realism and holism and other such issues (230).

Cohen explicitly adopts a Platonic metaphor when he argues that "facts cast normative light only by reflecting the light that fact-free first principles shine on them" (267). Plato refers often to the analogy with light to explain the relationship between ideas and objects of the world. He argues that the presence of objects that exhibit different colours and our ability to see things are insufficient unless a third element, the light, is taken into account. ${ }^{13}$ " [W] hen our eyes are directed towards things whose colours are no longer bathed in daylight, but in artificial light instead, then they are less effective and seem to be virtually blind, as if they didn't even have the potential for seeing clearly". However "when they are directed towards things which are lit up by the sun, they see clearly and obviously do have that potential" (508c-d).

This, Plato argues, is how we should think about our mind in relationship to ideas. When the objects to which it directs attention are "lit up by truth and reality, then it has [...] intelligent awareness and knowledge". But when they are in the dark or when nature corrupts them through generation and decay "then it has beliefs and is less effective because its beliefs chop and change, and under these circumstances it comes across as devoid of intelligence". For Plato, only "the sight of the character of goodness leads one to deduce that it is responsible for everything that is right and fine, whatever the circumstances". In the phenomenal realm goodness is "the progenitor of light and of the source of light, and in the intelligible realm it is the source and provider of truth and knowledge" (508 d- 508 e).

In a similar way, defenders of the fact-insensitivity of principles argue that if any facts support principles at all, it is only because they appeal to more ultimate factinsensitive principles. Affirming these principles survives the denial of contingent facts of the world, in the same way in which directing the mind to intelligible entities (like ideas) to explain why transitory objects are what they are, survives the decay of these objects. After a few steps in the correct chain of reasoning, fact-insensitive principles are able to explain how other principles are reflected by facts without need to appeal to examples in which those facts are displayed. As in Cohen's passage cited above, we do not find out what courage is by pointing at examples of courageous action, rather, it is because we

\footnotetext{
13 “Even if a person's eyes are capable of sight, and he's trying to use it, and what he's trying to use look at is coloured, the sight will see nothing and the colours will remain unseen unless there is also present an extra third thing which is made specifically for that purpose" (Plato [unknown] 1994: 507d-507e).
} 
have the idea of courage that we are able to identify such cases as cases of courageous action.

But the similarities between the defence of the fact-insensitivity of principles and the Platonic theory of ideas are not limited to the metaphors we have examined. Defenders of fact-insensitive normative principles and followers of the Platonic theory of ideas share the same process of reason-giving. In both cases, the answer to relevant "why" type of questions is obtained through a particular method of enquiry defined by Socrates as the "dialectical method". ${ }^{4}$ This is a way of proceeding through which reason seeks an explanation for why certain facts support principles and this explanation ultimately transcends the mere concatenation of these facts. It is given by fact-free principles, which are in turn intuitively clear. Existing factual properties of things, Socrates explains, are considered mere starting points but the grounds that explain why these things display precisely these properties cannot be identified with them. The process of reason giving takes us beyond the starting assumptions; these are considered "not as first principles, but only as [...] steps and points of departure" (511b). Dialectic, Socrates clarifies, is "the only field of enquiry whose quest for certainty causes it to uproot the things it takes for granted in the course of its journey [...] When the mind's eye is literally buried deep in mud, far from home, dialectics gently extracts it and guides it upwards" (533d).

Both defenders of the theory of ideas and advocates of the fact-insensitivity of principles ultimately rely on the evidence provided by intuitions to explain why anything grounds what it grounds. The typical method of proceeding in the Socratic case is to start by asking, for example, how a particular moral property could be defined (e.g. virtue, courage or justice). The objector comes up with an example of conduct in which one of these properties is displayed. Then Socrates responds by either challenging the example or illustrating the unforeseen consequences of that definition or by extending it to other cases that the objector had initially failed to take into account. The sequence of interrogation goes on until we encounter a self-evident more fundamental principle which is in turn assessed either against itself or against its consequences. In this case the philosopher is able to display something like the property of the "clarity of mind": the fundamental principles at the summit of our moral judgments appear to us as being obvious and if they survive the test they become part of a coherent system, whereas if they fail they are rejected. ${ }^{15}$

A similar dialectical approach seems also endorsed by defenders of the factinsensitivity of principles. Cohen reports admiration for the way in which first-order principles of justice are identified in Plato's Republic. "The lovers of sights and sounds" he

\footnotetext{
${ }^{14}$ Not to be confused with Hegelian and Marxian dialectic.

15 See the explanation of the editor in (Plato [unknown] 1994). For a further discussion of Plato's intuitionism see Dahl 1991.
} 
argues, think that it is enough to provide examples of just behaviour in order to reach the fundamental principles of justice. As Cohen further explains:

they scarcely recognize the question: What is justice, as such? In a world where the facts are F, they believe that $\mathrm{P}$ constitutes justice, and they do not abstract even so far as to see that they believe, independently of the facts, principles of the form: if $F$ then $P$. Plato thinks, and I agree, that you need to have a view of what justice itself is to recognize that justice dictates $\mathrm{P}$ when $\mathrm{F}$ is true. That is how justice transcends the facts of the world (291).

The commitment to a similar mode of reasoning is also apparent in the selfunderstanding of the difference between intuitionist approaches (some version of which is endorsed by both Plato and Cohen) and the constructivist method adopted by opponents of fact-insensitive principles (e.g. Rawls). ${ }^{16}$ In the former case, Cohen argues, "we determine the principles that we are willing to endorse through an investigation of our individual normative judgments on particular cases, and, while we allow that principles that are extensively supported by a wide range of individual judgments can override outlier judgments that contradict those principles, individual judgments retain a certain sovereignty." When proceeding in a similar fashion, he continues "we refine, and we thereby reach, our deepest normative convictions" and when facing a conflict between these first principles we are "simply to strike a balance by intuition, by what seems to us most nearly right". ${ }^{17}$

Both Platonists and defenders of the fact-insensitivity of principles therefore believe that the normative explanations we can obtain for any existent set of factual statements are bound to proceed upwards until they reach an ultimately fact-independent principle (or several such). Both moreover believe that our intuitions, especially when refined through philosophical reasoning, provide a credible enough guide on the definition, properties and overall plausibility of such ultimate fact-insensitive principles. For both there is no need for further proof to argue, for example, that justice (however we understand it) is what makes just acts just, or that the good (if there is any) is what makes good things good. In what follows I will refer to commitments of this form as an instance of self-predication (SP).

But before proceeding with the argument it may be necessary to clear the ground from a couple of fundamental critiques. Firstly, some might argue that even though Cohen relies on intuitions in order to clarify what justice is, that part of his argument is

\footnotetext{
${ }^{16}$ For a more detailed discussion of the dispute see (Ronzoni and Valentini 2008; Kurtulmus 2009; Jubb 2009)

${ }^{17}$ (Cohen 2008) citing Rawls.
} 
not related to his general defence of the relationship between facts and principles. However, I doubt that Cohen would want to see the two points isolated from each other in such a way. In Rescuing Justice, the argument on facts and principles serves his critique of Rawls's rival methodological approach (constructivism): it is invoked at various points to strengthen Cohen's arguments on the nature of justice and to clarify the distinction between fundamental principles of justice and rules of regulation. ${ }^{18}$ Even if we concede that one does not need to be an intuitionist to endorse Cohen's argument on the relationship between facts and principles, the two issues are by no means entirely unrelated. Exposing some flaws that might arise when investigating further their link helps to reconsider the larger methodological implications of the fact-insensitivity thesis.

Secondly, some might object to the analogy between the Platonic theory of ideas and the defence of fact-independent principles by emphasizing that the latter is only conditionally asserted whereas Plato's arguments are loaded with ontological judgments about the real structure of the world. Cohen, for example, argues that even if he ultimately agrees with Plato that justice is the same thing across and independently of history, that extreme anti-relativism is not part of the doctrine defended in his book that justice is fact-free (291). The reason for that claim is of course that in its weaker version the defence of the fact-insensitivity of principles is only conditional and takes the form: "if any facts support principles, then ... etc etc". In this case nothing needs to be conclusively said about the real structure and composition of our normative world.

Since this paper is concerned only with the logical structure of Plato's and Cohen's arguments, the distinction should in any case be irrelevant to the general point we are trying to make. However, it is also worth insisting that, on a more generous interpretation of Socrates' mission, the arguments provided in The Republic could also be considered conditional. At one point, after introducing the allegories of the Sun and of the cave as metaphors for discussing the mind's ascent to the idea of good, Socrates disarmingly admits to Glaucon that "only God knows if this is actually true". He then goes on to make several statements of the form "whether true or false, my opinion is that..." (517b). It is curious to observe Socrates confessing that he is, after all, expressing merely "an opinion", especially if we consider that at this stage of his thought, Plato has already distanced himself from the Socratic irony of the earlier dialogues. But with that more revisionist interpretation in mind, it may be easier to show how Plato could have been the first philosopher ever to doubt the validity of his own theory of ideas. This, at least, is what the

\footnotetext{
${ }^{18}$ Consider for example the following passage: "I believe that, whatever their content may be, fundamental principles of justice are in no way dependent on the nature of any facts. [...] I thereby affirm that constructivists miscast applied principles of justice to the role of fundamental ones" (281). For more evidence of the link see also how the "clarity of mind assumption" is invoked in the critique of constructivism (p. 279, note 6). The distinction between fundamental principles of justice and rules of regulation figures prominently in Cohen's critique of Rawls's theory of justice, see esp. ch. 7 of Rescuing Justice.
} 
devastating argument he introduces against himself in the dialogue entitled Parmenides goes on to show.

IV.

"It is rare enough to find a philosopher employing his best resources to construct an argument which, were it valid, would have destroyed the logical foundations of his life's work. What is rarer still and [...] absolutely without parallel in the pages of Western philosophy, is to find a man who faces such an emergency as Plato did" (Vlastos 1954). The emergency, known after Aristotle as the "Third Man argument" (Aristotle [unknown] 1998: esp. 90b17, 1079a13, 1039a2) erupts in one of the most complex Platonic dialogues: Parmenides. The text describes the encounter between a young philosopher named Socrates and the "venerable" Eleatic philosopher Parmenides who interrogates Socrates on the main definitions and fundamental premises of his own theory of ideas and then lays down a series of logical, epistemic and metaphysical challenges. Among those, the Third Man argument, is well-known for being one that Plato himself considered among the most intractable - a suspicion reinforced by the absence of an official response to it either in Parmenides itself or in any of the later dialogues. $^{19}$

Parmenides' reported challenge begins by inviting Socrates to confirm the relevance of the distinction between things in the factual world and the principles that they reflect. ${ }^{20}$ After obtaining Socrates endorsement of the distinction, Parmenides

\footnotetext{
${ }^{19}$ Here I cannot even begin to do full justice to the immense body of literature that the Third Man argument has generated. My reconstruction follows the path-breaking analysis of Gregory Vlastos, see (Vlastos 1954) and (Vlastos 1955) but my reconstruction of the arguments relies on the overlapping features of the many conflicting interpretations that Vlastos' analysis has generated rather than taking sides. Where taking sides has proved unavoidable, I have indicated in the footnotes which interpretation has been followed but I have done so without contributing anything new to that particular interpretation. Readers who are not familiar with Plato should note that much of the critical literature does not dispute the fact that the Third Man argument constitutes a valid logical inference. What commentators disagree upon is the extent to which Plato's theory of ideas has textual support to counter the Third Man objection, the consistency of jointly affirming two of its central premises and the plausibility and possible extension of the "self-predication" assumption. I agree with Wilfrid Sellars that there is no inconsistency in the joint affirmation of these premises (see (Sellars 1955) and I also agree with Sandra Peterson that the selfpredication assumption is a plausible one (see (Peterson 1973) but I do not have space here to further justify my claims. Overall, my paper is limited to considering how the objection could apply to the defence of the fact-insensitivity of principles; it does not enter the substantive controversy among Plato scholars.

${ }^{20}$ Socrates, he said, I admire the bent of your mind towards philosophy; tell me now, was this your own distinction between ideas in themselves and the things which partake of them? [...]And would you also make absolute ideas of the just and the beautiful and the good, and of all that class? - Yes, he said, I should" (Parmenides 130).
} 
continues to press. His argument is now targeted at the method Socrates adopts in the course of his dialectical enquiry: he wants to know "whether Socrates means "that there are certain ideas of which all other things partake, and from which they derive their names; that similars, for example, become similar, because they partake of similarity; and great things become great, because they partake of greatness; and that just and beautiful things become just and beautiful, because they partake of justice and beauty?" (Parmenides 131-2). And once again, Socrates agrees that this is what he means.

The logic of Socrates' enquiry is similar to that followed by defenders of fact-insensitive principles. We have observed the latter agree with the Socratic - Platonic method which brings them to identify first principles of justice by intuition, while relying on examples of just behaviour only as a way of starting their dialectical exercise. When asking why anything grounds what it grounds, defenders of fact-insensitive principles maintain that in the process of unearthing the reasons we have for devotion to specific normative commitments, we also discover our endorsement of superior and more fundamental factfree principles. If challenged by Parmenides to repeat why they think this is the case, they would answer by making the same intuitionist point that we have seen Socrates make: "you need to have a view of what justice itself is to recognize that justice dictates $\mathrm{P}$ when $\mathrm{F}$ is true" (291). But would they also be subject to the same objection we are about to outline?

To answer that question we need to consider the details of Parmenides challenge. The text reads as follows:

- $\quad$ I imagine that the way in which you are led to assume one idea of each kind is as follows:-You see a number of great objects, and when you look at them there seems to you to be one and the same idea (or nature) in them all; hence you conceive of greatness as one. ${ }^{21}$

- $\quad$ Very true, said Socrates.

- $\quad$ And if you go on and allow your mind in like manner to embrace in one view the idea of greatness and of great things which are not the idea, and to compare them, will not another greatness arise, which will appear to be the source of all these? ${ }^{22}$

- $\quad$ It would seem so.

- $\quad$ Then another idea of greatness now comes into view over and above absolute greatness, and the individuals which partake of it; and then another, over and above all these, by virtue of which they will all be great, and so each idea instead of being one will be infinitely multiplied. ${ }^{23}$

\footnotetext{
${ }^{21}$ First premise.

${ }^{22}$ Second premise.

${ }^{23}$ Conclusion.
} 
This is the crucial passage. The argument leads Parmenides to question the logical foundations of the entire theory of ideas because, if formalized, the challenge applies to any first principles that philosophers could claim to have identified through the method that Socrates describes (and defenders of the thesis we are examining seem to endorse). ${ }^{24}$ The contemporary reader should not be misled by the metaphysical oddity of the specific example (the concept of greatness) that Parmenides provides to challenge the Platonic theory of ideas. As we shall shortly see, the argument is especially valid if we substitute "greatness" with evaluative predicates of the kind that defenders of the fact-insensitivity thesis endorse. ${ }^{25}$ To understand this point, we need to unpack the logical premises that contribute to the argument, and consider how they are also present in the thesis we are examining.

V.

To see the logical structure of the "Third Man", consider a simpler formulation of Parmenides' argument taking the example of justice: ${ }^{26}$

1. There are a plurality of circumstances we call just (fact).

2. If a plurality of just circumstances are all of them just, there is at least one principle of justice in virtue of which all of them are just (oneover-many).

2a. Any plurality of just circumstances and the principle of justice in virtue of which they are all just is itself a plurality (condition for pluralities).

3. Justice is such that if any circumstance that we call just is inspired by its principles then that circumstance counts as just (self-predication).

3a. No just circumstance is just in virtue of itself (non-self explanation).

4. There are infinitely many principles of justice (conclusion).

\footnotetext{
24 "These, Socrates, said Parmenides, are a few, and only a few of the difficulties in which we are involved if ideas really are and we determine each one of them to be an absolute unity. He who hears what may be said against them will deny the very existence of them-and even if they do exist, he will say that they must of necessity be unknown to man; and he will seem to have reason on his side, and as we were remarking just now, will be very difficult to convince; a man must be gifted with very considerable ability before he can learn that everything has a class and an absolute essence; and still more remarkable will he be who discovers all these things for himself, and having thoroughly investigated them is able to teach them to others". Ibid.

${ }^{25}$ On the plausibility of self-predication in these cases see the discussion on Pauline predicates in Peterson 1973: 457-462.

${ }^{26}$ I owe this simplification to (Peterson 1973) who is in turn inspired by (Strang 1963) and (Geach 1965)
} 
The first premise of the argument is a fact. The second premise says that if a number of things, a, b, c, participate in $\mathrm{P}$, there must be another predicate $\mathrm{P} 1$ that has an extension such that if $a, b, c$, participate in it, then they are $P$. The third premise says that if $\mathrm{a}, \mathrm{b}, \mathrm{c}$, and $\mathrm{P} 1$ are all $\mathrm{P}$, then there must be another predicate, $\mathrm{P} 2$ that has an extension such that if $\mathrm{a}, \mathrm{b}, \mathrm{c}$, and $\mathrm{P} 1$ participate in $\mathrm{P}$, then they are $\mathrm{P}$. The conclusion asserts that this process can go on infinitely.

Now let us see how this argument could apply to the premises of an example endorsed by defenders of the fact-insensitivity thesis, that of keeping promises.

Step 1: It is good to keep promises.

Argument:

1) There are a plurality of circumstances in which a certain principle (e.g. keeping promises) $\mathrm{P}$ applies (fact).

Step 2: When promises are kept, promisees can successfully pursue their projects.

\section{Argument:}

2) If there is an explanation for why a certain principle $P$ is predicated of a plurality of circumstances, there is at least one other principle P1 in virtue of which we apprehend those circumstances as circumstances of which $\mathrm{P}$ is predicated (one-over-many).

Step 3: If promisees can successfully pursue their projects when promises are kept, we should help them pursue their projects.

\section{Argument:}

3a. If there is an explanation for why a certain principle $\mathrm{P}$ and another principle $\mathrm{P} 1$ are predicated of a plurality of circumstances, then there is another principle P2 in virtue of which we understand those circumstances as circumstances in which P and P1 are predicated (self-predication).

3b. No plurality of circumstances explains itself (non-self explanation).

Conclusion: There are infinitely many principles. 
The first premise (1) is simply a restatement of the starting point for defenders of the fact-insensitivity thesis. The second premise (2) recalls what defenders of factinsensitivity believe, which is that if any facts support principles (call them type 1 principles), then there are further principles (call them type 2 principles) that explain why those facts support those initially considered (type 1) principles. The first leg of the third premise says that if there are further (type 2) principles that explain why facts support initially considered (type 1) principles, then there are even more ultimate (type 3) principles that explain why the further (type 2) principles explain the facts that support the initially considered (type 1) principles. The second leg of the third premise repeats the non-self explanation premise: that for any set of circumstances, $\mathrm{P}$ and the explanation for $\mathrm{P}$ cannot be the same proposition. ${ }^{27}$ The conclusion is that, given these premises, the search can go on forever.

As we have seen, the premises that contribute to generate this infinite regress are the same in both the standard interpretation of Socrates' account of ideas in Parmenides and in the defence of fact-insensitive principles. Both theories hold three assumptions: the one-over-many assumption; the self-predication assumption; and the non-selfexplanation assumption. The first is needed to show why anything grounds what it grounds and we have seen it appear in both the first and the second premise of Cohen's argument. The second is embedded in the identification of more and more fundamental principles via the intuitionist method that both Cohen and Plato endorse. The third premise is necessary to deny the possibility of concluding the process of reason-giving by simply appealing to the self-evidence of fact-sensitive principles. Given these premises, infinite regress seems hard to avoid, and Parmenides' challenge remains a plausible one.

Defenders of fact-insensitive principles would probably object to this finding by arguing that it is possible to block the infinite regress by reminding us of the third requirement of their thesis, which claims that the process of reason-giving when explaining why facts support principles is bound to stop at some point. Let us examine further this argument.

VI.

The denial of an endless sequence of interrogation in the process of reason-giving (that is to say: the validity of the third premise mentioned at the beginning of this paper) is grounded on three further claims.

\footnotetext{
${ }^{27}$ Recall that the restriction that the second premise of Cohen's argument (p. 236) affects what is affirmed in the first premise: "it is allowed here to be an explanation (albeit a singularily unsatisfying one) of why $p$ (if it indeed does) supports $\mathrm{p}$, that they are the same proposition. The restriction introduced in the second premise is precisely to deny what is allowed in the first premise: self-explanation.
} 
First claim:

G3.a. It is implausible to think that a sequence of interrogation can go on indefinitely. If you disagree try to construct one (237).

Second claim:

G.3.b. It is implausible to think that a sequence of interrogation can go indefinitely: it would require something like an infinite nesting of principles, and few will think that there exist a relevantly infinite number of principles (237).

Let us leave aside the challenge of the first claim ${ }^{28}$ and focus on the second one. The difficulty here is that the claims seem incompatible with the requirements of the overall argument. Indeed, G.3.b contributes to establishing the third premise at the price of violating one of the thesis central stipulations. Knowing the number (or nesting) of principles implies taking a stand on a central meta-ethical dispute and saying something positive about the objective existence of normative principles (as opposed to their subjective or merely conditional endorsement). So accepting that claim is incompatible with the idea a thesis that professes itself neutral with regard to central meta-ethical disputes (257). The difficulty with the latter claim (G.3.b) is that it makes the validity of the premise it is supposed to ground depend on taking a stand with regard to an issue that consistency requires better be ignored. If the thesis is not interested in the nature and status of specific principles (central meta-ethical dispute) but only in what people are committed to when they make certain utterances (as a matter of logic), how can establishing the thesis depend on what people think about how many principles there are or, for that matter, how many principles there are, regardless of people think? In trying to establish the validity of the third premise, the claim violates the thesis' meta-ethical neutrality.

Third claim: the clarity of mind requirement:

G.3.c. It is implausible to think that a sequence of interrogation can go on indefinitely.

The further explanation for this premise is that an unending sequence of justification would run against the requirement that "she who affirms $\mathrm{P}$ has a clear grasp of what her principles are and of why she holds them for we can surely say that a person who cannot complete the indicated sequence, because she has to go on forever, does not know why she holds the principles that she does" (237).

\footnotetext{
${ }^{28}$ The weakness of this claim has already been noted by Thomas Pogge, see footnote 2, above.
} 
Clearly, this is not a psychological requirement for, we are told, the thesis is indifferent to particular psychological circumstances (256). More persuasively, it is a claim about the structure of our normative commitments, or rather the structure of the principles that, we think, constitute "the objective normative truth, if there is such a thing". The clarity of mind requirement postulates that the fact-insensitivity thesis applies to anyone who has a "clear grasp both of what her principles are and of why she holds them (where grasping "why she holds them is short for knowing what she thinks are the grounds of the principles" rather than for "what causes her to hold them")" (233).

Cohen recognizes that a similar requirement may encounter obstacles if someone insists that norms are formed under factual constraints and that it does not make sense for us to confront absurd or counterfactual situations (for example that of a zygote/fetus that progresses towards a less and less baby-like condition) with a view to disclosing the ultimate principles on which they may be grounded. In this case, he concedes that objectors might be right to accept the three premises but deny the clarity of mind requirement (247). But this move seems hard to justify. If the clarity of mind requirement is necessary (as shown in the formulation of G.3.c. above) to render acceptable the third premise of the argument, it is not clear how one could reject that requirement and continue to endorse "the three premises". Indeed, denying the validity of the clarity of mind will commit us to denying the validity of at least one premise of the argument: the third one (G.3). Having done that, we are authorized to proceed as if the argument were composed only by the two premises that we have already assessed.

It is also important to notice that the clarity of mind requirement stands in some tension with the non-self-explanation assumption introduced in section 2 above. If the search for fact-supporting principles is bound to stop at the identification of one factinsensitive normative principle (or several such), what is the source of validity of that ultimate principle? Intuitionists would probably answer that the more ultimate principle we have encountered is, well, "intuitively" plausible. To say that ultimate principles are intuitively plausible is to say that they are valid in and of themselves. This in turn is similar to endorsing claims of the form: "justice is just". But doesn't this violate the central explanatory stipulation with which we started, that the explanation of why a claim is true cannot be the claim itself? If it does, the non-self-explanation premise is endangered. If it does not, the clarity of mind assumption would end up undermined.

VII.

The objection that Plato raised in Parmenides against his own theory of ideas is a serious one. As we have illustrated, that objection interestingly applies to one of the most ambitious recent attempts to explain the structure of our normative commitments and the weight that factual judgments ought to bear in moral reasoning. The obstacles that the 
theory faces are not external; they are internal to the assumptions with which the argument starts. Given these obstacles, defenders of fact-insensitive principles face a choice. If they abandon the "non-self-explanation" assumption they will have trouble initiating the sequence of interrogation from which the demonstration of fact-insensitive principles is supposed to follow. If they abandon the "self-predication" assumption they will have to re-negotiate the intuitive plausibility of ultimate fact-insensitive principles. If they drop the "one-over-many assumption" they will deprive principles of their explanatory potential.

If the argument presented here on the relationship between facts and principles is valid, the limitations of discovering fact-independent principles are not psychological or epistemological but logical. This is an unfortunate consequence for an argument which was supposed to only make a point about logic in the first place. But the implications may be even wider. They force us to reconsider the way in which we go about constructing the relationship between facts and principles, widely understood, and between normative ideals and political practice, more narrowly considered. To end up where we started, a stronger argument is needed if we are to be convinced that, for example, socialism is an ideal worth defending even without any support from the facts rather than the real movement which abolishes the present state of affairs.

\section{Bibliography}

Aristotle, and H. C. Lawson-Tancred. 1998. The metaphysics, Penguin classics. London: Penguin.

Cohen, Gerald A. 2008. Rescuing justice and equality. Cambridge: Harvard University Press.

Cohen, G. A. 2009. Why not socialism? Princeton: Princeton University Press.

Gilabert, Pablo. 2011. Feasibility and Socialism. Journal of Political Philosophy 19 (1): 5263.

Norman O. Dahl, "Plato's Defense of Justice," Philosophy and Phenomenological Research, 1991 51: 809-34.

Geach, P.T. 1965. The Third Man Again. In Studies in Plato's Metaphysics, edited by R. E. Allen. New York. 
Jubb, Robert. 2009. Logical and epistemic foundationalism about grounding: The triviality of facts and principles. Res Publica 15 (4): 337-353.

Kurtulmus, A. Faik. 2009. Rawls and Cohen on facts and principles. Utilitas 21 (4): 489505.

Marx, Karl. 2000. Selected Writings. Edited by David McLellan. Oxford: Oxford University Press.

Peterson, Sandra. 1973. A Reasonable Self-Predication Premise for the Third Man Argument. The Philosophical Review 82 (4):451-470.

Plato. [unknown] 1994. The Republic. Translated by R. Waterfield. Oxford: Oxford University Press.

Plato. [unknown] Parmenides. Translated by B. Jowett. Oxford: Oxford University Press.

Ronzoni, Miriam, and Laura Valentini. 2008. On the meta-ethical status of constructivism: reflections on G.A. Cohen's 'Facts and Principles'. Politics Philosophy Economics ; 7: 403-422.

Pogge, Thomas. 2008. Cohen to the rescue! Ratio 21:454-475.

Sellars, Wilfrid. 1955. Vlastos and "The Third Man. The Philosophical Review 64 (3):405437.

Strang, Colin. 1963. 'Plato and the Third Man. Proceedings of the Aristotelian Society Supplementary Volume 37:147-164.

Vlastos, Gregory. 1954. The Third Man Argument in the Parmenides. The Philosophical Review 63 (3):319-349.

- - - 1955. Addenda to the Third Man Argument: A Reply to Professor Sellars. The Philosophical Review 64 ( 3):438-448.

Ypi, Lea. 2011. Global justice and avant-garde political agency. Oxford: Oxford University Press. 